\title{
Sweet-Tasting Ionic Conjugates of Local Anesthetics and Vasoconstrictors
}

\author{
John K. Neubert ${ }^{1}$, Alexander A. Oliferenko ${ }^{2}$, Polina V. Oliferenko ${ }^{2}$, Sergey V. Emets ${ }^{2}$, David A. Ostrov ${ }^{3}\left({ }^{10}\right.$, \\ Gary I. Altschuler ${ }^{4}$, Joe Calkins ${ }^{5}$, Jay Wickersham ${ }^{1}$, Robert Hromas ${ }^{6}$ and Iryna O. Lebedyeva ${ }^{5, *}$
}

check for

updates

Citation: Neubert, J.K.; Oliferenko, A.A.; Oliferenko, P.V.; Emets, S.V.;

Ostrov, D.A.; Altschuler, G.I.; Calkins,

J.; Wickersham, J.; Hromas, R.;

Lebedyeva, I.O. Sweet-Tasting Ionic

Conjugates of Local Anesthetics and Vasoconstrictors. Molecules 2021, 26, 983. https://doi.org/10.3390/ molecules 26040983

Academic Editors: Roman Dembinsk and Igor Alabugin

Received: 25 December 2020

Accepted: 4 February 2021

Published: 12 February 2021

Publisher's Note: MDPI stays neutral with regard to jurisdictional claims in published maps and institutional affiliations.

Copyright: (c) 2021 by the authors. Licensee MDPI, Basel, Switzerland This article is an open access article distributed under the terms and conditions of the Creative Commons Attribution (CC BY) license (https:/ / creativecommons.org/licenses/by/ $4.0 /)$.
1 Department of Orthodontics, College of Dentistry, University of Florida, Gainesville, FL 32610, USA; jneubert@dental.ufl.edu (J.K.N.); jWickersham@gmail.com (J.W.)

2 EigenChem Technologies Inc., Alachua, FL 32615, USA; a.oliferenko@eigenchem.com (A.A.O.); p.oliferenko@eigenchem.com (P.V.O.); s.emets@eigenchem.com (S.V.E.)

3 Department of Pathology, Immunology and Laboratory Medicine, College of Medicine, University of Florida, Gainesville, FL 32610, USA; ostroda@pathology.ufl.edu

4 Altschuler Periodontic and Implant Center, Gainesville, FL 32606, USA; gary.altschuler@ufl.edu

5 Department of Chemistry and Physics, Augusta University, Augusta, GA 30912, USA; jcalkins3@gmail.com

6 Department of Medicine, College of Medicine, University of Florida \& Shands, Gainesville, FL 32610, USA; rhromas@ufl.edu

* Correspondence: ilebedyeva@augusta.edu; Tel.: +1-706-729-2456

\begin{abstract}
Local anesthetics are widely utilized in dentistry, cosmetology, and medicine. Local anesthesia is essential to providing a pain-free experience during dental and local surgeries as well as cosmetic procedures. However, the injection itself may produce discomfort and be a source of aversion. A novel approach toward the taste modulation of local anesthetics is proposed, in which the anesthetics of the "-caine" family serve as cations and are coupled with anionic sweeteners such as saccharinate and acesulfamate. Ionic conjugates of vasoconstrictor epinephrine such as epinephrine saccharinate and epinephrine acesulfamate have also been synthesized. Novel ionic conjugates were developed using anion exchange techniques. Reported compounds are sweet-tasting and are safe to use both topically and as injections.
\end{abstract}

Keywords: anesthesia; local anesthetic; vasoconstrictor; sweetener; injectable anesthetic; lidocaine; local anesthesia; dental; epinephrine

\section{Introduction}

Local anesthesia is essential for suppressing pain during medical [1,2], cosmetic [3-5], or dental procedures [6]. However, patients often perceive the receipt of local anesthesia as the most painful and sometimes only objectionable part of these procedures [7]. Therefore, patients may avoid obtaining cosmetic [8], medical [9], or dental care [10]. The bitter taste of the commonly used hydrochloride salts of local anesthetics [11,12] adds to the general displeasure that patients experience prior to dental procedures [13]. Further, hydrochloride salts that are commonly used in compositions formulated for local anesthesia, e.g., compositions comprising hydrochloride salt of a local anesthetic and epinephrine hydrochloride, have an acidic $\mathrm{pH}$ of between 3.5 and 5.5 [14] and, consequently, can cause additional pain and tissue damage upon injection $[15,16]$. As a result, there is an existing need in compositions for local anesthetics with higher $\mathrm{pH}$ that do not taste bitter or create an objectionable feeling upon injection.

The use of saccharinate as a counter anion in ciprofloxacin saccharinate and other fluoroquinolone antimicrobials due to its sweet taste, high aqueous solubility, and capability to form salts and co-crystals has been reported (Figure 1) [17]. Substitution of the conventional chloride anion with saccharinate in tramadol hydrochloride (Figure 1) improved the release profile and stability of the active ingredient [18]. Moreira et al. reported the synthesis of acesulfame, saccharin, and docusate salts for pharmaceuticals such as local anesthetics, as 
well as salicylic acid, flurbiprofen, diclofenac, and flufenamic acid (Figure 1). Saccharinate and acesulfamate have also been employed to synthesize choline salts with the sweeteners [19]. Rogers et al. mentioned saccharin and acesulfame as counter ions for active pharmaceutical, biological, and nutritional ingredients [20], as well as provided several examples of the discussed ionic liquids. In our previously reported work, injectable salts of lidocaine, such as lidocaine acesulfamate, saccharinate, and gluconate, were developed and studied for their taste, efficacy, and toxicity [21].

Cation:<smiles>O=C(O)Cc1ccccc1Nc1c(Cl)cccc1Cl</smiles>

Diclofenac<smiles>O=C(O)c1cn(C2CC2)c2cc(F)cc([NH+]3CCNCC3)c2c1=O</smiles>

Ciprofloxacin<smiles>COc1cccc(C2(O)CCCCC2C[N+](=O)[O-])c1</smiles>

Tramadol

Anion:<smiles>C[N+](C)(C)CCO</smiles><smiles>CCNCC(C)(C)C(=O)Nc1c(C)cccc1C</smiles>

Choline<smiles>CC1=CC(=O)NS(=O)(=O)O1</smiles>

Acesulfame<smiles></smiles>

Saccharin

Figure 1. Pharmaceuticals with saccharin and acesulfame as counter ions, which have been reported in the literature.

The bitter taste of hydrochloride salts of local anesthetics [11,22] has been hidden by glutamate salts [23], dexmedetomidine as an oral premedication [24], or a formulation of a sweet-tasting composition containing a local anesthetic and a sweetener [25]. The problem of painful injections has been addressed through the creation of high-pH buffer solutions for procedures that require injections [26] as well as through the development of new procedures that would minimize the pain resulting from the injection [7].

In this work, we have solved two problems: the bitter taste of local anesthetics and the low $\mathrm{pH}$ values of local anesthetic composition solutions, which results in a stinging effect upon injection. The synthesis of novel ionic conjugates has also been expanded to major representatives of injectable local anesthetic cations such as articaine, bupivacaine, mepivacaine, oxybuprocaine, prilocaine, and a vasoconstrictor epinephrine. Sweetener anions were represented by saccharin and acesulfame. Hydrochloride salts of these widely used local anesthetics have been subjected to the ion exchange reaction with metal salts of ionic sweeteners, which resulted in novel, highly soluble, and intrinsically sweet chemical compounds. The exchange of epinephrine hydrochloride for sweetener anions such as saccharin and acesulfame was also demonstrated, as epinephrine is a vasoconstrictor and an ingredient in a wide range of injectable formulations. Aqueous solutions of the synthesized compounds have been studied for their $\mathrm{pH}$ values, palatability, and in vivo thermal pain analgesic properties.

\section{Results and Discussion}

\subsection{Synthesis of Novel Acesulfame and Saccharin Salts of Local Anesthetics}

Acesulfame salts of mepivacaine $3 \mathbf{a}$, bupivacaine $3 \mathbf{b}$, prilocaine $3 \mathbf{c}$, articaine $3 \mathbf{d}$, and oxybuprocaine $3 \mathbf{e}$ were synthesized in $96-98 \%$ yields. Products were formed as a white semisolid (3a), colorless oil (3b), a yellowish oil (3e), and white solids (3c, 3d). Saccharin 
salts of mepivacaine $4 a$, bupivacaine $4 \mathrm{~b}$, prilocaine $4 \mathrm{c}$, articaine $4 \mathrm{~d}$, and oxybuprocaine $4 \mathbf{e}$ were synthesized in $95-99 \%$ yields and products were isolated as a colorless oil (4a), a white solid (4b and $4 c)$, and a yellow oil (4d, $4 \mathbf{e})$. To synthesize a library of novel sweet anesthetics of the "-caine" family, the caine hydrochlorides $\mathbf{1}$ such as mepivacaine $\mathrm{HCl}$, bupivacaine $\mathrm{HCl}$, prilocaine $\mathrm{HCl}$, and articaine $\mathrm{HCl}$ were mixed with either potassium acesulfame $\mathbf{2 a}$ or sodium saccharin hydrate $\mathbf{2 b}$ in dry $\mathrm{MeCN}$ for $4 \mathrm{~h}$ at $50^{\circ} \mathrm{C}$. The reaction mixture was then filtered to isolate the sodium or potassium chloride byproduct. After the solvent was evaporated, products $3 \mathbf{a}-\mathbf{d}$ and $\mathbf{4 a}-\mathbf{d}$ were isolated in quantitative yields. Oxybuprocaine salts $3 \mathbf{e}$ and $4 \mathbf{e}$ were synthesized by mixing equimolar quantities of oxybuprocaine hydrochloride and potassium acesulfame $\mathbf{2} \mathbf{a}$ or sodium saccharinate $\mathbf{2} \mathbf{b}$ in EtOH at room temperature overnight, thereby leading to the formation of $3 \mathbf{e}$ and $4 \mathbf{e}$ in 98 and $97 \%$, respectively (Figure 2). The straightforward nature of the counter ion exchange from the chloride to the anion of a sweetener confirms that either method would be suitable for the synthesis of stable caine saccharinates or acesulfamates in high yields (Table 1).<smiles>O=C1NS(=O)(=O)c2ccccc21</smiles><smiles>CC1=CC(=O)N(S(=O)(=O)O)S(=O)(=O)O1</smiles><smiles>CC1=CC(=O)NS(=O)(=O)O1</smiles>

Figure 2. General scheme for the synthesis of saccharin and acesulfame salts of local anesthetics of the caine family.

Table 1. Structures of the new products.

(n)


Table 1. Cont.

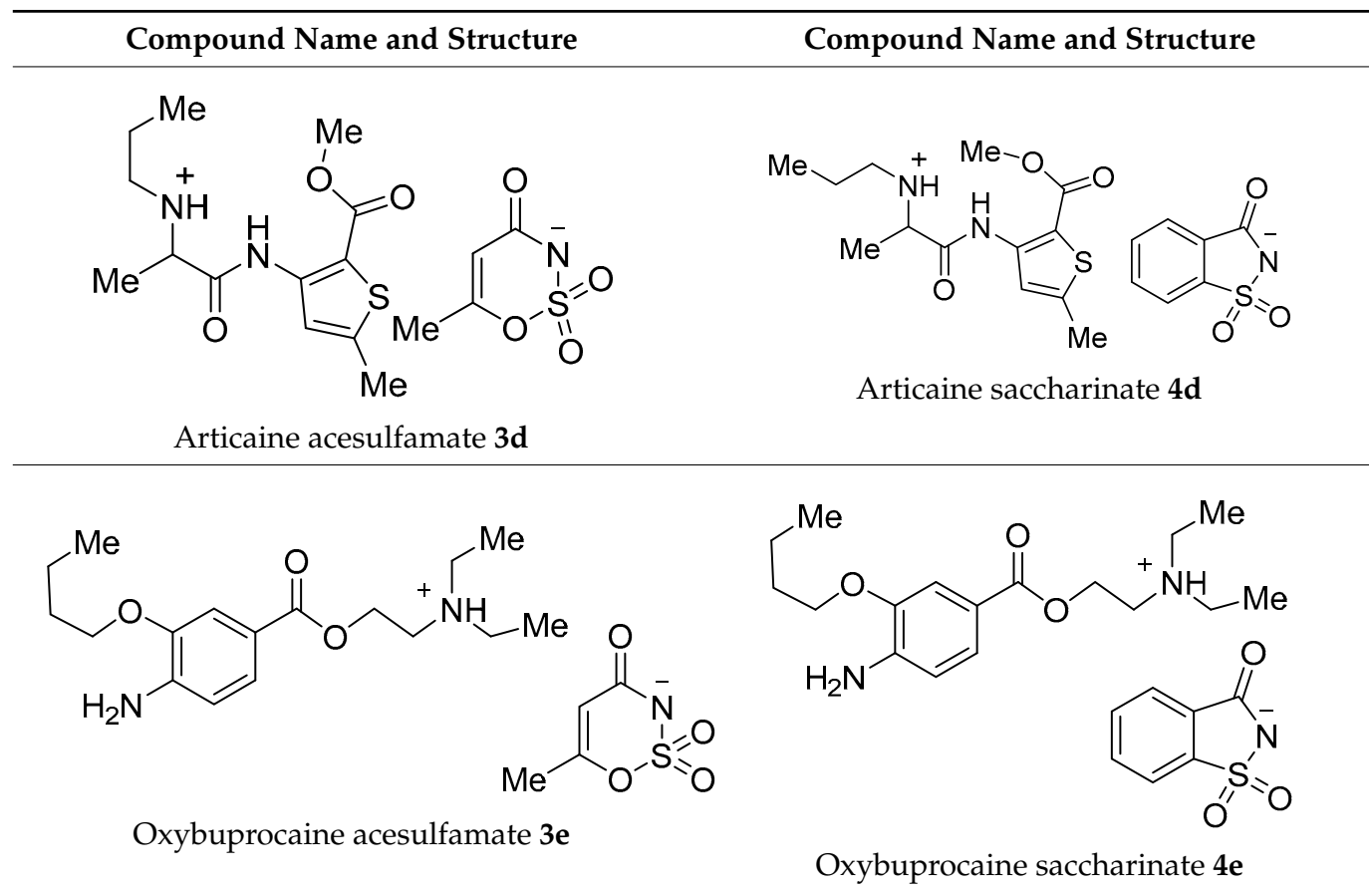

Epinephrine acesulfame $\mathbf{6 a}$ and epinephrine saccharinate $\mathbf{6 b}$ were synthesized in a similar manner to compounds $\mathbf{3 a}-\mathbf{d}$ and $\mathbf{4 a}-\mathbf{d}$. Equimolar quantities of epinephrine hydrochloride 5 and a sweetener $2 \mathbf{a}$ or $\mathbf{2 b}$ were stirred in acetonitrile for $4 \mathrm{~h}$ at $50{ }^{\circ} \mathrm{C}$. After the reaction mixture was filtered and the solvent had evaporated, products $\mathbf{6 a}$ and $\mathbf{6 b}$ were isolated in $99 \%$ and $96 \%$, respectively (Figure 3).

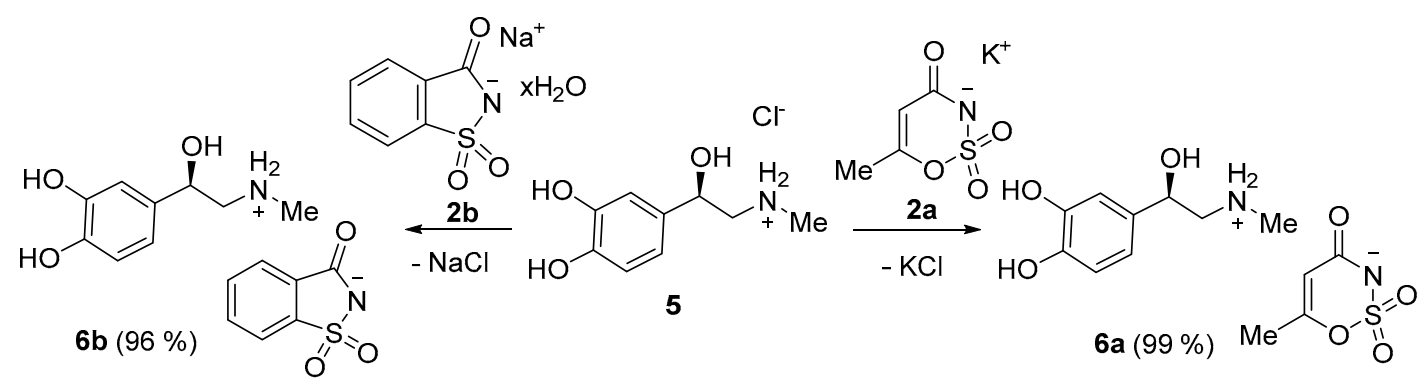

Figure 3. Synthesis of epinephrine acesulfamate $\mathbf{6 a}$ and epinephrine saccharinate $\mathbf{6 b}$.

${ }^{1} \mathrm{H}$ NMR signals for salts 3, 4, and 6 revealed signals of the anesthetic moieties with the substituted aromatic signals in the weak field and also of the aliphatic protons in the strong field at $1-4.5 \mathrm{ppm}$. Acesulfame moiety in the salts was characterized by the singlet of the $\mathrm{CH}$ at around $5.5 \mathrm{ppm}$ and the singlet of the methyl group at around $1.9 \mathrm{ppm} .{ }^{1} \mathrm{H}$ signals for saccharin moiety were revealed as a multiplet signal of four protons at around 6.90-7.20 ppm. ${ }^{13} \mathrm{C}$ signals for the acesulfame moiety of 3,4 , and $\mathbf{6}$ were revealed at around $18-20 \mathrm{ppm}$ for the methyl group; carbon of the CO group gave a signal at around $170 \mathrm{ppm}$, while the characteristic peak of the $\mathrm{CH}$ group was found at around $102 \mathrm{ppm}$. Saccharin salts of 3, 4, and 6 gave characteristic peaks at around 171-173 ppm for the CO signal, four signals of aromatic moiety at around 128-130 ppm, and two signals at around 137 and $145 \mathrm{ppm}$ for the C-C carbons of the aromatic ring. Signals of aromatic and aliphatic protons for the anesthetic cations were also found for all the compounds 3a-e and $4 \mathbf{a}-\mathbf{e}$. Mass peaks for the novel salts were identified at positive and negative ionization modes using ESI/MS. Mass signals under positive ionization were as follows: 247.1800 for 3a and 
247.1799 for $4 \mathbf{a}$, which correspond with mepivacaine residue. Signals 289.2262 for $3 \mathbf{b}$ and 279.2266 for $4 \mathbf{b}$ correspond with ions of positively charged bupivacaine. Positively charged signals of 221.1645 for $3 c$ and 221.1641 for $4 c$ represent prilocaine moiety. Articaine cation was detected at 285.1261 for $3 \mathbf{d}$ and 285.1261 for $4 \mathbf{d}$. Epinephrine cation was detected at 184.0964 for $\mathbf{6 a}$ and 184.0966 for $\mathbf{6 b}$. Acesulfame anions were detected at around $\mathrm{m} / \mathrm{z}$ 161 for $3 \mathbf{a}-3 \mathbf{e}$ and $\mathbf{6 a}$ while saccharin anions were observed at around $\mathrm{m} / \mathrm{z} 181$ for $4 \mathbf{a}-4 \mathbf{e}$ and $\mathbf{6 b}$. NMR and MS data for all products has been summarized in the Supplementary Materials section.

\section{2. $p H$ Study of the Aqueous Solutions of Novel Salts}

The $\mathrm{pH}$ values of the aqueous solutions of $\mathbf{3 a}-\mathbf{e}, \mathbf{4 a - e}$, and $\mathbf{6 a}-\mathbf{b}$ were measured and compared to the $\mathrm{pH}$ values of original salts 1, 2, and 5. $\mathrm{pH}$ values of all compound solutions in deionized water were measured at $10 \%, 5 \%$, and $2 \%$ concentrations. Thus, sodium saccharin monohydrate $\mathbf{2 a}$ and potassium acesulfame $\mathbf{2} \mathbf{b}$ revealed $\mathrm{pH}$ values of between $5.75(10 \%)$ and $5.98(2 \%)$ for $2 a$, and $5.63(10 \%)$ and $6.19(2 \%)$ for $\mathbf{2 b}$. From this data, it can be concluded that the use of saccharin and acesulfame as counter ions as part of the local anesthetic molecule will increase the $\mathrm{pH}$ of the latter, leading to a reduction in the stinging effect upon injection. The $\mathrm{pH}$ values of the solution of mepivacaine acesulfame 3a and mepivacaine saccharinate $4 \mathbf{a}$, both at $10 \%$ concentration, were somewhat higher than the $\mathrm{pH}$ of mepivacaine hydrochloride $3.73(10 \%)$. Bupivacaine hydrochloride revealed the $\mathrm{pH}$ of 4.23 at $10 \%$, whereas bupivacaine acesulfamate $3 \mathbf{b}$ and bupivacaine saccharinate $4 \mathbf{b}$ showed $\mathrm{pH}$ values of 4.25 and 3.84 at $10 \%$, respectively. Bupivacaine salts also showed solubility problems with hydrochloride starting materials as well as buvivacaine acesulfamate $\mathbf{3 b}$ and bupivacaine saccharinate $4 \mathrm{~b}$ products. The $\mathrm{pH}$ values of prilocaine acesulfamate $3 \mathrm{c}$ and prilocaine saccharinate $4 \mathrm{c}$ at $10 \%$ were significantly higher than that of prilocaine hydrochloride, which was 2.10 at $10 \%$. Articaine hydrochloride showed lower solubility in water than did the products $\mathbf{3} \mathbf{d}$ and $\mathbf{4 d}$, which affected the measurement of $\mathrm{pH}$ values in a water solution. Thus, the $\mathrm{pH}$ of articaine hydrochloride at $10 \%$ was 4.22 , whereas articaine acesulfamate $\mathbf{3 d}$ and articaine saccharinate $\mathbf{4 d}$ showed $\mathrm{pH}$ levels of 3.50 and 3.83 at $10 \%$, respectively. Oxybuprocaine hydrochloride revealed a pH of 4.42 at $10 \%$ water concentration, while its salts showed $\mathrm{pH}$ levels of 4.68 and 4.70 at $10 \%$ for $3 \mathbf{e}$ and $4 \mathbf{e}$, respectively. Vasoconstrictor epinephrine hydrochloride 5 showed a pH value of 3.57 at $10 \%$ water concentration, whereas epinephrine acesulfamate $\mathbf{6 a}$ and epinephrine saccharinate $\mathbf{6 b}$ had $\mathrm{pH}$ values of 4.01 and 3.57 at $10 \%$ concentration, respectively. All concentrations were measured weight-by-volume. $\mathrm{pH}$ values for all product concentrations have been summarized in the Supplementary Materials section.

\subsection{Thermal Pain Testing}

Response to hindpaw heat pain was determined by placing unrestrained animals on a clear glass platform under a small plastic cage and habituating the animals for $5 \mathrm{~min}$. A radiant heat source was aimed directly under the ventral hindpaw surface and the time to paw withdrawal was recorded as described previously [27]. Baseline responses were obtained under naïve conditions (e.g., no injection), while post-treatment effects of caine salts 3 and 4, and vehicle (water), were assessed for $10 \mathrm{~min}$ following plantar injection $(100 \mu \mathrm{L})$. A cutoff of $32 \mathrm{sec}$ was used to prevent tissue damage.

\subsection{Statistical Analyses}

An analysis of variance was used to evaluate the effects of treatment on hindpaw withdrawal latency (SPSS Inc). When significant differences were found, post hoc comparisons were made using the Tukey post hoc test. ${ }^{*} p<0.05$ was considered significant in all instances.

There was a significant treatment effect on hindpaw latency $(\mathrm{F7}, 63=8.238, p<0.001)$, with articaine saccharinate (AS) $4 \mathbf{d}$, articaine acesulfamate (AA) 3d, bupivacaine acesulfamate (BA) 3b, bupivacaine saccharinate (BS) $4 b$, prilocaine acesulfamate (PA) $3 c$, prilocaine 
saccharinate (PS) 4c, and mepivacaine acesulfamate (MA) 3a producing significantly higher latencies as compared to the baseline (naïve) (Figure 4).

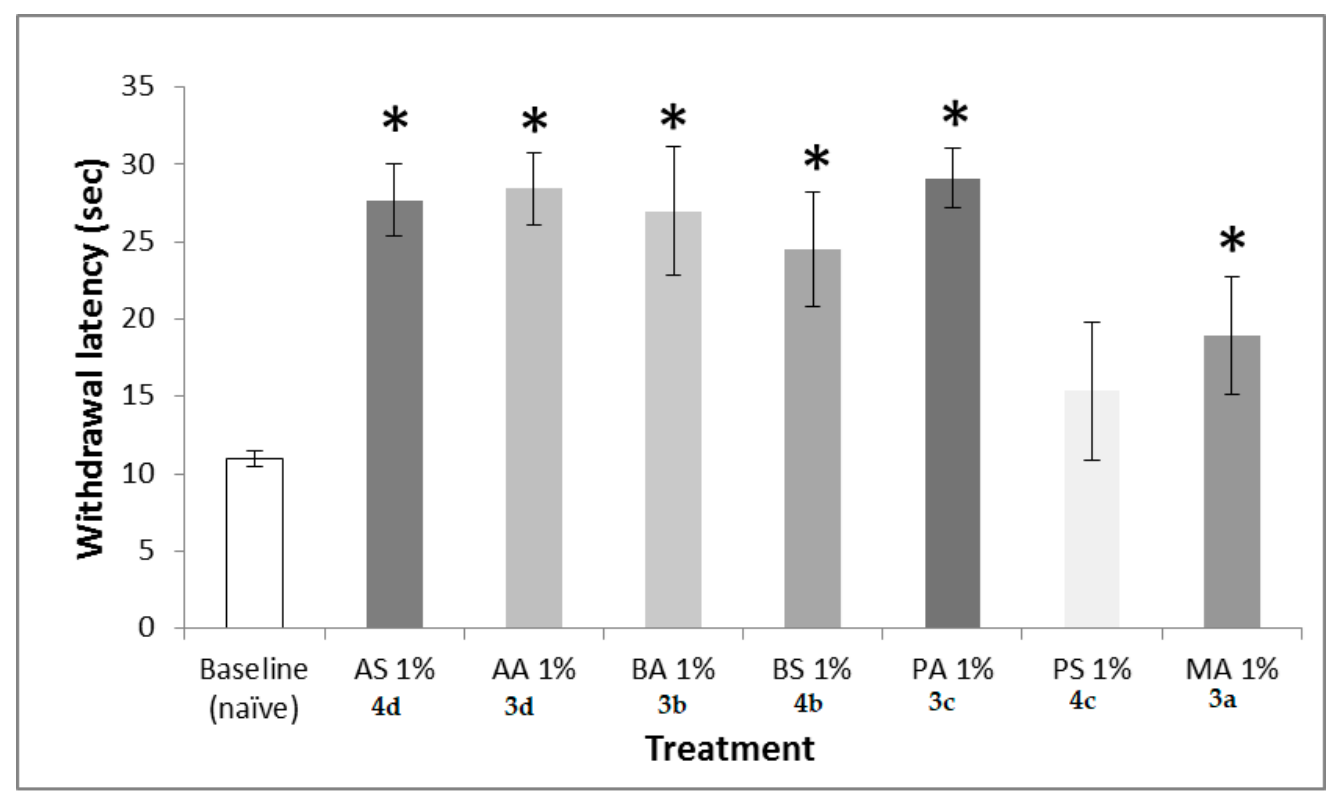

Figure 4. Thermal hindpaw latency following local anesthetic injection. One-percent solutions were injected into the hindpaws of animals and withdrawal latency to a thermal stimulus was recorded 10 min post-injection. All caine salts ( $\mathrm{N}=10$ animals/group) except PS (prilocaine saccharinate, $4 \mathrm{c}$ ) produced a significant increase in latency time as compared to that of non-injected naïve animals, indicating that the caine salts were effective at inhibiting pain. ${ }^{*} p<0.05$

\subsection{Palatability Assessment}

Animals were food-fasted (12-15 h) prior to testing. Animals were then placed in the Orofacial Pain Assessment Device (OPAD, Stoelting Company, Wood Dale, IL, USA), which consisted of a holding chamber and a bottle containing various test solutions. Animals ( $\mathrm{N}=5$ /solution) were placed in the holding chamber and allowed access to the solution for $7 \mathrm{~min}$. The number of solution licking events was automatically recorded (Figure 5).

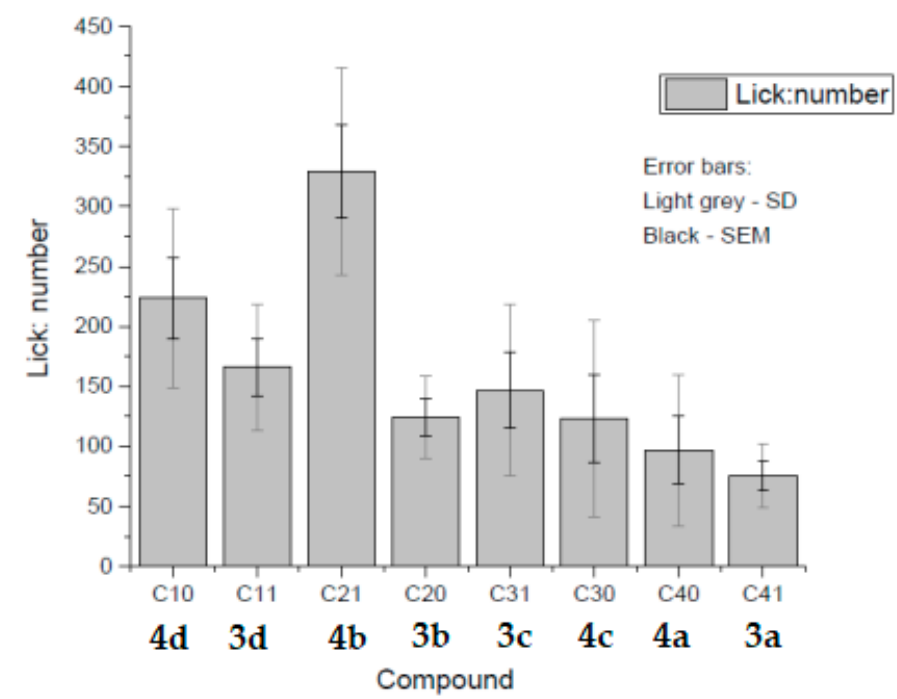

Figure 5. Relative palatability of each compound. A palatability test was conducted for the following anesthetics: articaine saccharinate (C10) $4 \mathbf{d}$, articaine acesulfamate (C11) 3d, bupivacaine saccharinate (C20) $4 \mathbf{b}$, bupivacaine acesulfamate (C21) $3 \mathbf{b}$, prilocaine saccharinate (C30) $4 \mathbf{c}$, prilocaine acesulfamate (C31) 3c, mepivacaine saccharinate (C40) 4a, and mepivacaine acesulfamate (C41) 3a. 
Rats successfully consumed the different caine salt solutions. Note that our previous study [28] demonstrated that rats given a $0.1 \%$ saccharin solution had $109 \pm 40$ licks (in a 20-min test session).

\section{Materials and Methods}

Melting points were determined on a capillary point apparatus with a digital thermometer and are uncorrected. ${ }^{1} \mathrm{H}$ NMR spectra were recorded at $500 \mathrm{MHz}$ while ${ }^{13} \mathrm{C}$ NMR spectra were recorded at $125 \mathrm{MHz}$ on a Bruker spectrometer (Bruker, Billerica, MA, USA) at room temperature. Chemical shifts are reported in ppm relative to TMS as the internal standard $\left({ }^{1} \mathrm{HNMR}\right)$ or to the residual solvent peak $\left({ }^{13} \mathrm{C} \mathrm{NMR}\right)$. HRMS were recorded on a QTof-USA (Thermo Fisher Scientific, Waltham, MA, USA) spectrometer operating in the ESI mode. Elemental analysis for CHN elements was carried out using $2400 \mathrm{CHNS}$ Organic Elemental Analyzer 100V. All commercially available substrates were used as received, without further purification.

\subsection{Animal Studies}

Male Sprague Dawley rats (200-300g, Charles River Laboratories, Wilmington, MA, USA) were housed in groups of two and were maintained in a standard 12-h light/dark cycle. Testing was completed during the light portion of the cycle, between 09:00-12:00. Animals were placed in the behavioral procedure room $30 \mathrm{~min}$ prior to testing, to acclimate. When the animals were not in testing sessions, food and water were made available to them ad libitum. Animal testing procedures complied with the ethical guidelines and standards established by the University of Florida's Institutional Animal Care and Use Committee and with the Guide for Care and Use of Laboratory Animals (National Research Council Guide for the Care and Use of Laboratory Animals. Washington, D.C., National Academy Press; 1996). Animal Use Approval: The University of Florida's Institutional Animal Care and Use Committee (IACUC) protocol \#201207690; date of approval: 12/11/2012.

\subsection{Synthesis of Acesulfamates and Saccharinates for the Caines $\mathbf{3 a}-\mathbf{d}$, and $\mathbf{4 a - \mathbf { d }}$}

To the solution of a hydrochloride salt of a corresponding caine $1(1.0 \mathrm{mmol})$ in MeCN (15 mL), the equimolar quantity of sweetener sodium salt (sodium 6-methyl-1,2,3oxathiazin-4-olate 2,2-dioxide $0.185 \mathrm{~g}$ for 2 a or sodium benzo[d]isothiazol-3-olate 1,1dioxide $0.205 \mathrm{~g}$ for $\mathbf{2 b}$ ) was added. The mixture was then stirred for $4 \mathrm{~h}$ at $50{ }^{\circ} \mathrm{C}$. After the reaction was completed, the reaction mixture was filtered through the 22-micron membrane filter and the filtrate was taken to dryness. Next, diethyl ether $(3 \times 25 \mathrm{~mL})$ was added to the product and was evaporated to give compounds $\mathbf{3 a}-\mathbf{d}$ and $\mathbf{4 a}-\mathbf{d}$ in quantitative yields. All final products, $\mathbf{3 a}-\mathbf{d}$ and $\mathbf{4} \mathbf{a}-\mathbf{d}$, are water-soluble ionic conjugates consisting of the anion of a sweetener (acesulfame or saccharine) and a representative of a caine family (mepivacaine, bupivacaine, prilocaine, articaine) as a cation.

\subsection{Synthesis of Oxybuprocaine Acesulfame $\mathbf{3 e}$ and Saccharinate $4 \mathbf{e}$}

To a solution of oxybuprocaine hydrochloride $(0.048 \mathrm{~g}, 0.139 \mathrm{mmol})$ in $2 \mathrm{~mL}$ of EtOH was added a suspension of acesulfame potassium $(0.028 \mathrm{~g}, 0.139 \mathrm{mg})$ or sodium saccharinate $(0.028 \mathrm{~g}, 0.139 \mathrm{mg})$ in $2 \mathrm{~mL}$ of EtOH. The reaction mixture was stirred at room temperature overnight. This reaction mixture was then filtered, and the solvent evaporated. The residue was dissolved in $3 \mathrm{~mL}$ of MeCN. After filtration, the products were obtained as yellow oils in a quantitative yield.

\subsection{Synthesis of Epinephrine Acesulfamate $\mathbf{6 a}$ and Epinephrine Saccharinate $\mathbf{6 b}$}

To the solution of epinephrine hydrochloride 5 (1.0 mmol, $0.22 \mathrm{~g})$ in $\mathrm{MeCN}(15 \mathrm{~mL})$, the equimolar quantity of sweetener sodium salt (sodium 6-methyl-1,2,3-oxathiazin-4-olate 2,2-dioxide $0.185 \mathrm{~g}$ for $\mathbf{2 a}$ and sodium benzo[d]isothiazol-3-olate 1,1-dioxide $0.205 \mathrm{~g}$ for $\mathbf{2 b}$ ) was added. The mixture was then stirred for $4 \mathrm{~h}$ at $50{ }^{\circ} \mathrm{C}$. After the reaction was completed, the reaction mixture was filtered through the 22-micron membrane filter and the filtrate 
was taken to dryness. Next, diethyl ether $(3 \times 25 \mathrm{~mL})$ was added to the product and it was evaporated to give the compounds $6 \mathbf{a}, \mathbf{b}$ in quantitative yields.

\section{Conclusions}

Novel sweet-tasting salts of anesthetics of the "-caine" family, such as articaine, bupivacaine, mepivacaine, oxybuprocaine, and prilocaine, as well as salts of vasoconstrictor epinephrine, have been synthesized. Ionic conjugates have been developed by coupling hydrochloride salts of local anesthetics with sodium saccharinate and potassium acesulfamate, using either in $\mathrm{MeCN}$ or EtOH as a solvent. An analogous approach was employed to synthesize epinephrine salts with the saccharin and acesulfame sweetener counter ions. Chloride anion, which is largely responsible for the bitterness of hydrochloride salts, has been removed from the ionic liquids in the form of sodium or potassium chloride. This chemical approach toward making ionic conjugates differs greatly from reported attempts to mask the bitterness of the hydrochloride salts of anesthetics by mixing them with sweeteners or taste modifiers. Such an anion exchange results in the formation of novel, highly water-soluble, and sweet-tasting stable salts with zero osmolarity and a higher bioavailability due to the use of more lipophilic anions [29]. Animal studies of palatability of the novel salts have proved that novel caine saccharinates and acesulfamates possess a more pleasant taste than do their hydrochloride analogs. During the thermal pain testing, there was a significant treatment effect on hindpaw withdraw latency $(\mathrm{F} 7,63=8.238, p<0.001)$, with novel ionic conjugates producing significantly higher latencies as compared to the baseline (naïve). The $\mathrm{pH}$ study of the aqueous solutions of all synthesized salts demonstrated that acesulfame and saccharin salts of local anesthetics showed higher $\mathrm{pH}$ values of water solutions of $10 \%, 5 \%$, and $2 \%$ concentrations for articaine, bupivacaine, mepivacaine, oxybuprocaine, and prilocaine saccharinates and for acesulfamates as compared to their original hydrochloride salts. Aqueous solutions of novel epinephrine salts also revealed an increase in $\mathrm{pH}$ at $10 \%$ compared to analogous solutions of epinephrine hydrochloride. It is expected that more basic products will not have the stinging effect upon injection, unlike their counterparts with lower $\mathrm{pH}$ values.

Supplementary Materials: The following are available online: Detailed analysis of compound structure for all synthesized compounds. Table S1: $\mathrm{pH}$ of aqueous solutions of all synthesized salts and original compounds. ${ }^{1} \mathrm{H},{ }^{13} \mathrm{C}$ NMR, and HRMS data on all synthesized compounds.

Author Contributions: Conceptualization, R.H., I.O.L., A.A.O., D.A.O., G.I.A.; methodology, S.V.E., I.O.L., J.W., J.C.; validation, A.A.O., D.A.O.; formal analysis, J.K.N., P.V.O.; investigation, S.V.E., A.A.O., J.K.N., J.W., J.C.; data curation, R.H.; writing—original draft preparation, I.O.L.; writingreview and editing, P.V.O., supervision, G.I.A.; All authors have read and agreed to the published version of the manuscript.

Funding: This research received no external funding.

Institutional Review Board Statement: Animal testing procedures complied with the ethical guidelines and standards established by the University of Florida's Institutional Animal Care and Use Committee and with the Guide for Care and Use of Laboratory Animals (National Research Council Guide for the Care and Use of Laboratory Animals. Washington, D.C., National Academy Press; 1996.

Informed Consent Statement: Not applicable.

Data Availability Statement: The data presented in this study are available in supplementary material.

Conflicts of Interest: The authors declare no conflict of interest.

Sample Availability: Samples of the compounds are not available from the authors. 


\section{References}

1. Kjaergaard, M.; Moiniche, S.; Olsen, K. Wound infiltration with local anesthetics for post-operative pain relief in lumbar spine surgery: A systematic review. Acta Anaesthesiol. Scand. 2012, 56, 282-290. [CrossRef]

2. Park, K.K.; Sharon, V.R. A review of local anesthetics: Minimizing risk and side effects in cutaneous surgery. Derm. Surg. 2016, 43 , 173-187. [CrossRef]

3. Santoni-Rugiu, P.; Sykes, P.J. A History of Plastic Surgery; Springer: Berlin/Heidelberg, Germany, 2007; pp. 157-166.

4. Stoelting, R.K.; Miller, R.D. Basics of Anesthesia; Churchill Livingstone: London, UK, 2006.

5. Goudra, B.; Arora, S. Out of Operating Room Anesthesia; Springer: Berlin/Heidelberg, Germany, 2017.

6. Peden, C.J.; Cook, S.C. Sedation for dental and other procedures. Anaesth. Intens. Care 2014, 15, 362-365. [CrossRef]

7. Strazar, A.R.; Leynes, P.G.; Lalonde, D.H. Minimizing the pain of local anesthesia injection. Plast. Reconstr. Surg. 2013, 132, 675-684. [CrossRef]

8. Roderick, F.A. Anesthesia for the cosmetic patient: An American perspective. In International Textbook of Aesthetic Surgery; Scudeli, N., Toth, B.A., Eds.; Springer: Berlin/Heidelberg, Germany, 2016; pp. 75-82.

9. Burkle, C.; Pasternak, J.; Armstrong, M.; Keegan, M. Patient perspectives on informed consent for anaesthesia and surgery: American attitudes. Acta Anaesthesiol. Scand. 2013, 57, 342-349. [CrossRef] [PubMed]

10. Appukuttan, D.; Subramanian, S.; Tadepalli, A.; Damodaran, L.K. Dental anxiety among adults: An epidemiological study in South India. N. Am. J. Med. Sci. 2015, 7, 13-18. [CrossRef] [PubMed]

11. Ando, T.; Shimoo, Y.; Nakasato, M.; Yoshida, H. Development and clinical evaluation of new topical anesthetic formulations for dental care. Biol. Pharm. Bull. 2016, 39, 423-427. [CrossRef] [PubMed]

12. Wei, Y.; Nedley, M.P.; Bhaduri, S.B.; Bredzinski, X.; Boddu, S.S. Masking the bitter taste of injectable lidocaine $\mathrm{HCl}$ formulation for dental procedures. Aaps Pharmscitech. 2015, 16, 455-465. [CrossRef] [PubMed]

13. Hotta, M.; Endo, S.; Tomita, H. Taste disturbance in two patients after dental anesthesia by inferior alveolar nerve block. Acta Otolaryngol. 2002, 546, 94-98. [CrossRef] [PubMed]

14. Frank, S.C.; Lalonde, D.H. How acidic is the lidocaine we are injecting, and how much bicarbonate should we add? Can. J. Plast. Surg. 2012, 20, 71-73. [CrossRef]

15. Breu, A.; Rosenmeier, K.; Kujat, R.; Angele, P.; Zink, W. The cytotoxicity of bupivacaine, ropivacaine, and mepivacaine on human chondrocytes and cartilage. Anesth Analg. 2013, 117, 514-522. [CrossRef] [PubMed]

16. Kyttä, J.; Heinonen, E.; Rosenberg, P.; Wahlström, T.; Gripenberg, J.; Huopaniemi, T. Effects of repeated bupivacaine administration on sciatic nerve and surrounding muscle tissue in rats. Acta Anaesthesiol. Scand. 1986, 30, 625-629. [CrossRef] [PubMed]

17. Romañuk, C.; Linck, Y.G.; Chattah, A.; Monti, G.; Cuffini, S.; Garland, M.; Baggio, R.; Manzo, R.; Olivera, M. Crystallographic, thermal and spectroscopic characterization of a ciprofloxacin saccharinate polymorph. Int. J. Pharm. 2010, 391, 197-202. [CrossRef] [PubMed]

18. Bartholomaus, J.; Kugelmann, H.; Ziegler, I. Sustained-Release form of Administration Containing Tramadol Saccharinate; Patent and Trademark Office: Alexandria, VA, USA, 2001.

19. Nockemann, P.; Thijs, B.; Driesen, K.; Janssen, C.R.; Van Hecke, K.; Van Meervelt, L.; Kossmann, S.; Kirchner, B.; Binnemans, K. Choline saccharinate and choline acesulfamate: Ionic liquids with low toxicities. J. Phys. Chem. B. 2007, 111, 5254-5263. [CrossRef]

20. Rogers, R.; Daly, D.T.; Swatloski, R.P.; Hough, W.L.; Davis, J.H.; Smiglak, M.; Pernak, J.; Spear, S.K. Multi-Functional Ionic Liquid Compositions for Overcoming Polymorphism and Imparting Improved Properties for Active Pharmaceutical, Biological, Nutritional, and Energetic Ingredients; Patent and Trademark Office: Alexandria, VA, USA, 2012.

21. Lebedyeva, I.O.; Oliferenko, A.A.; Oliferenko, P.V.; Hromas, R.A.; Neubert, J.K.; Caudle, R.M.; Wickersham, J.; Castleman, W.L.; Altschuler, G.I.; Ostrov, D.A.; et al. Ionic conjugates of lidocaine and sweeteners as better tasting local anesthetics for dentistry. J. Mater. Chem. B 2015, 3, 8492-8498. [CrossRef]

22. Poulsen, S.; Koch, G.; Espelid, I.; Haubek, D. Pediatric Dentistry: A Clinical Approach, 3th ed.; Haukali, G., Lundeberg, S., Ostergaard, B.H., Haubek, D., Eds.; Wiley-VCH: Weinheim, Germany, 2016; pp. 1-4.

23. Tengler, M.; McMahen, R. Compositions and Methods of Making Rapidly Dissolving Ionically Masked Formulations; Patent and Trademark Office: Alexandria, VA, USA, 2014.

24. Keles, S.; Kocaturk, O. The Effect of Oral Dexmedetomidine premedication on preoperative cooperation and emergence delirium in children undergoing dental procedures. Biomed. Res. Int. 2017, 2017, 6742183. [CrossRef]

25. Moreira, D.N.; Fresno, N.; Pérez-Fernández, R.; Frizzo, C.P.; Goya, P.; Marco, C.; Martins, M.A.P.; Elguero, J. Brønsted acid-base pairs of drugs as dual ionic liquids: NMR ionicity studies. Tetrahedron 2015, 71, 676-685. [CrossRef]

26. Kuivalainen, A.M.; Ebeling, F.; Rosenberg, P. Warmed and buffered lidocaine for pain relief during bone marrow aspiration and biopsy: A randomized and controlled trial. Scand. J. Pain 2014, 5, 43-47. [CrossRef]

27. Hargreaves, K.; Dubner, R.; Brown, F.; Flores, C.; Joris, J. A new and sensitive method for measuring thermal nociception in cutaneous hyperalgesia. Pain 1988, 32, 77-88. [CrossRef]

28. Anderson, E.M.; Mills, R.; Nolan, T.A.; Jenkins, A.C.; Mustafa, G.; Lloyd, C.; Caudle, R.M.; Neubert, J.K. Use of the operant orofacial pain assessment device (OPAD) to measure changes in nociceptive behavior. J. Vis. Exp. 2013, 10, e50336. [CrossRef]

29. Smith, L.J.; Shih, A.; Miletic, G.; Miletic, V. Continual systemic infusion of lidocaine provides analgesia in an animal model of neuropathic pain. Pain 2002, 97, 267-273. [CrossRef] 